\title{
Products Sanitary Surveillance: Latex Condom on the Bias of the Sanitary Risk
}

\author{
Janete Teixeira Duarte*, Antonio Eugenio C.C de Almeida and Shirley de Mello Pereira Abrantes
}

National Institute of Quality Control in Health/Oswaldo Cruz Foundation, Brazil

\begin{abstract}
Objective: Health products can be marketed in Brazil after registration in the Health Ministry. Male condoms are considered health products and are compulsorily certified following RDC 62/2008 regulation. Condom sanitary control must follow the certification regulation however is impractical due to great sample size (548 units for each lot). An appropriate technical surveillance should be designed to condom sanitary control.
\end{abstract}

Methods: Two different batches were purchased directly from the manufacturer. And three different brands, being one of them similar to the batches acquired directly from the manufacturer, were acquired in several establishments in Brazil, and the total amount was the sum of several different lots for each of the chosen brands. It was incorporated geoprocessing technique to maintain the traceability of the lots collected in the trade. Analyzes were performed according to the criteria established in Brazilian National Health Oversight Agency Resolution no. RDC 62/2008. Non compliant samples results were sent to Sanitary Surveillance and actions were requested to collect non compliant lots samples, according to the sampling established by RDC 62/2008. Samples were analyzed by the laboratory. The reports are sent to the Sanitary Surveillance for the necessary measures.

Results: It was observed that three different lots found nonconformity in at least one of the analyzes and, in some cases, as our sample $\mathrm{N}$ is a variation of lots of a given brand, the non-compliance occurred in a lot that was considered separately, do not we would have enough to perform the analyzes.

Conclusion: The development of this technical surveillance model provides the monitoring actions of male condoms throughout the country, since from a perspective of Sanitary Surveillance, a unique nonconforming unit has serious implications for public health.

Keywords: Male condoms; Technical surveillance; Public health; Sanitary surveillance

\section{Introduction}

The incidence of Sexually Transmitted Infections (STIs) has increased in recent years and is considered a public health problem. This increase is a result of low socioeconomic and cultural conditions, lack of adequate sex education, especially aimed at young people. Today, sexually transmitted diseases are among the most common diseases in the world $[1,2]$.

Since the late 1980s, the potential impact of Human Immunodeficiency Virus (HIV) became apparent, and the World Health Organization Global Acquired Immunodeficiency Disease Program was implemented. As part of this program, the importance of condoms was recognized, and the specifications of the World Health Organization (WHO) have been prepared in order to allow both the WHO as other buyers acquire good quality products for HIV prevention [3].

WHO warns that if condoms are properly designed with adequate elasticity and strength, uniformity and free of perforations, significantly reduce the risk. However, they are not perfect. The condom made of latex may vary according to the lot and to differences in manufacturing technology, resulting in considerable variation in the quality. From the view point of contraception, the condom would have failure margin in order of 4 to 8 in Pearl index - that is, 4 to 8 unwanted pregnancies in 100 women who use the method, each year [4]

The quality of the condoms available in Brazil has been widely debated since 1987, when condoms were included in the category of pharmaceuticals, remaining under the jurisdiction of the Agência Nacional de Vigilância Sanitária (ANVISA, Brazilian Sanitary Surveillance Agency) of the Brazilian Health Ministry. Condom samples undergo tests that include the measurement of their dimensions (length, width and thickness), bursting volume and bursting pressure, as well as inspection to detect the presence of holes or other defects. Accuracy in labeling and the integrity of the packaging are also assessed. Sampling procedures in Brazil are in accordance with ISO $2859[5,6]$ and ANVISA Board Resolution no. RDC 62/2008, for lot sizes of 150,001-500,000 [7]. The sampling procedures for inspection by attributes (ISO 2859) constitute a recognized standard that specifies a sampling inspection system, indexed in terms of the acceptable quality level (AQL). The objective is to induce suppliers to maintain a level of quality which is at least equal to the limiting quality specified by the customer. The ISO 2859 sampling procedures for inspection by attributes define the acceptance criteria, the level of inspection (I, II or III) and the inspection regime based on the size of the lot [5].

The primary focus of the Brazilian Sistema Unico de Saúde (SUS, Unified Health Care System) guidelines for decentralization is comprehensiveness of care, with priority given to prevention and community participation. Health oversight is not only a part of the responsibilities of the SUS but has a priority character due to its essentially preventive nature. In this way, ANVISA corresponds to a space of governmental intervention - through its functions and tools, to work in the interest of public health [8].

*Corresponding author: Janete Teixeira Duarte, National Institute of Quality Control in Health/Oswaldo Cruz Foundation, Department of Chemistry, 4365, Manguinhos, Rio de Janeiro, Rio de Janeiro 21040900, Brazil; Tel: 552138655292; E-mail: janete.duarte@incqs.fiocruz.br

Received May 09, 2017; Accepted May 24, 2017; Published May 31, 2017

Citation: Duarte JT, de Almeida AECC, de Mello Pereira Abrantes S (2017) Products Sanitary Surveillance: Latex Condom on the Bias of the Sanitary Risk. J AIDS Clin Res 8: 700. doi: 10.4172/2155-6113.1000700

Copyright: (C) 2017 Duarte JT. This is an open-access article distributed under the terms of the Creative Commons Attribution License, which permits unrestricted use, distribution, and reproduction in any medium, provided the original author and source are credited. 
In the programmatic plan devised by the Brazilian government, there is an evident effort to integrate STI/AIDS prevention into the public health care network resulting from the decentralization of the SUS. The National STI/AIDS Program has sponsored descriptive studies and has developed systems for monitoring the management of programmed actions, as well as the attitudes, behaviors and practices of the populace. Nevertheless, studies evaluating prevention strategies and practices are extremely rare [9-11].

Although use of the male condom, one the main means of preventing STIs and to the unwanted pregnancy is considered simple and inexpensive, it requires sophisticated oversight. Therefore, the actions of Sanitary Surveillance become essential in monitoring this product against possible risks in Public Health.

This study aimed to develop a model capable of enabling the National Sanitary Surveillance System to play its role in the monitoring of male condoms commercialized in Brazil, since as a public policy, the Sanitary Surveillance differs from the other and unlikely to improve, through effective operation, planned, avoiding overlapping actions or lack of them, monitoring the quality of goods and products for health in post-marketing, a fundamental aspect.

\section{Method}

Two different batches, identified as Male Condoms Direct Producer (PMDP 1 and PMDP 2), were purchased directly from the manufacturer. Lots PMDP 1 and PMDP 2 had 820 units in each, making a total of 1640 units.

We acquired three different brands in several establishments in Brazil. Due to the difficulty of acquiring the number of units established in the sampling plan for quality control of condoms, we formed this total with the sum of several different lots for each of the chosen brands. Sprayed male condom samples were identified as Commercially Sprayed Male Condoms (PMPC). To select the brands to compose the PMPC lots, the criterion of random choices was used through the records of the male condoms contained in the Anvisa database. Lots PMPC 1, PMPC 2 e PMPC 3 had 660, 600, 600 units in each, respectively.

We incorporate geoprocessing techniques to maintain the traceability of the lots collected in the trade. Condoms were tested following the criteria established by RDC 62 for quality control testing of condoms as shown in Table 1.

The dimensional properties consist in measuring the length, width and thickness of the condom. In general, the product dimensions vary within the length ranges from 160 to $200 \mathrm{~mm}$, width of 45 to 60 $\mathrm{mm}$ and thickness 0.03 to $0.09 \mathrm{~mm}$. The width defines the size of the condom and refers primarily to the perimeter (twice the flat width, semicircle) $[12,13]$. In general, the length distribution within a batch and among batches of the same manufacturer shows the homogeneity of the manufacturer of the production process.
In all Standards existing checking holes is considered the most important test. We use two different methods in this evaluation, the electric and the visual. In the electrical fills the suspended condom with an electrolytic aqueous solution of sodium hydroxide: the passage of electric current indicates the existence of holes. In the visual fill the suspended condom with water. The both results methods have equivalence [14].

Package integrity evaluates the primary packaging violability. It can be accomplished by wet or dry. In use the wet to be easily visible due to the formation of bubbles when the packaging has some hole or a defect in the seal $[15,16]$.

The bursting volume must be $\geq 16.0 \mathrm{dm}^{3}$ for condoms with a width $\leq 50.0 \mathrm{~mm} ; \geq 18.0 \mathrm{dm}^{3}$ for condoms with a width $>50.0 \mathrm{~mm}$ and $<56.0 \mathrm{~mm}$; and $\geq 22.0 \mathrm{dm}^{3}$ for condoms with a width $\geq 56.0 \mathrm{~mm}^{8}$. The value of bursting pressure required is $1 \mathrm{kPa}$ and it does not depend on the width of the condom $[12,17,18]$. Bursting volume and bursting pressure were measured using an 8 head automated inflation system (Enersol, Sydney, Australia). During the insufflation test, nearly the entire condom is inflated like a balloon, stretching the latex film until it ruptures, thereby indicating its maximum resistance. The inflation system is accompanied by software [14] that logs the pressure and volume at bursting. The compressed air that supplies the system is generated by a dry, oil-free air compressor. The flow of compressed air was set at $24-30 \mathrm{dm}^{3} \mathrm{~min}^{-1}$, as defined in the standards. For each condom, the bursting pressure $(1 \mathrm{kPa}=1 \mathrm{~N}$ force applied uniformly over an area of $1 \mathrm{~m}^{2}$ ) and bursting volume (in $\mathrm{dm}^{3}$ ) were logged via the EInflation3 software [15].

Table 2 shows the requirements used to assess the quality of condoms in ISO 4074, WHO, RDC 62/2008.

In addition to the physical tests, the complementary tests for microbiological evaluation and cytotoxicity were focused in this study.

\section{Results}

The Table 3 shows the mean values of the dimensional properties found for all laboratory batches identified.

\section{Volumetric and burst pressure capacity}

The test results amount of non-conforming samples to volumetric and burst pressure capacity for the laboratory lots are showed at Table 4.

Regarding the results of the volumetric pressure and overflow test, 5 nonconforming units were found in Table 3, the manufacturers use the term "defect" instead of "non-conforming". If the individual parameters were considered, we would have 5 non-conforming units in volume and 3 nonconforming units in pressure. Thus, by the individual parameters, we would have 8 nonconforming units. The Figures 1 and 2 show the graphs of the volumetric capacity and overflow tests for laboratory lots.

\begin{tabular}{|c|c|c|c|c|}
\hline Essay & AQL & Number assessed units & $\begin{array}{l}\text { Number most accept non- } \\
\text { conforming units }\end{array}$ & $\begin{array}{l}\text { Number of non-conforming units } \\
\text { that rejects the lot }\end{array}$ \\
\hline Dimensions (length, width, thickness) & 4,0 & 13 & 1 & 2 \\
\hline Holes check & 0,25 & 315 & 2 & 3 \\
\hline Package Integrity & 2,5 & 20 & 1 & 2 \\
\hline Volumetric capacity and burst pressure & 1,5 & 200 & 7 & 8 \\
\hline Packaging and labeling & 1,0 & 13 & 0 & 1 \\
\hline
\end{tabular}

AQL: Acceptable Quality Level 


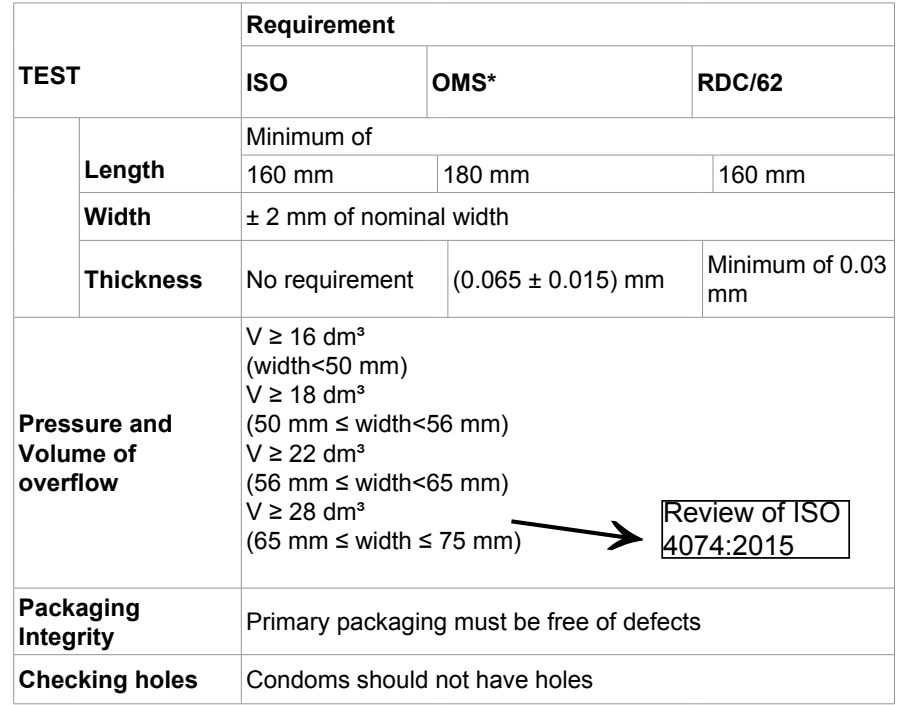

*The WHO specification for the width requirement also prescribes a tolerance of \pm $1 \mathrm{~mm}$ on the average of 13 measurements

Table 2: Requirements used to assess the quality of condoms in ISO $4074, \mathrm{WHO}$, RDC 62/2008.

\begin{tabular}{|l|c|c|c|}
\hline \multicolumn{4}{|c|}{ Average Values Found } \\
\hline & Length $(\mathbf{m m})$ & Width $(\mathbf{m m})$ & Thickness $(\mathbf{m m})$ \\
\hline PMDP1 & $187.1 \pm 2.60$ & $52.5 \pm 0.4$ & $0.031 \pm 0.0017$ \\
\hline PMDP2 & $187.5 \pm 2.14$ & $52.2 \pm 0.2$ & $0.031 \pm 0.001$ \\
\hline PMPC1 & $186.5 \pm 3.04$ & $51.8 \pm 0.7$ & $0.032 \pm 0.002$ \\
\hline PMPC2 & $193.6 \pm 1.04$ & $51.4 \pm 0.52$ & $\mathbf{0 . 0 2 2} \pm 0.0032$ \\
\hline PMPC3 & $195.5 \pm 2.93$ & $51.6 \pm 0.51$ & $0.05 \pm 0.007$ \\
\hline
\end{tabular}

*PMDP 1 and 2 - Male Condoms Direct from the Producer

${ }^{* *}$ PMPC 1, 2 and 3 - Male Condoms Sprayed in Trade

Table 3: The mean values of the dimensional properties found for all laboratory batches identified.

\begin{tabular}{|c|c|c|c|c|}
\hline AMOSTRAS & N & p & V & total \\
\hline PMDP 1 & 200 & 00 & 00 & 00 \\
\hline PMDP 2 & 200 & 00 & 00 & 00 \\
\hline PMPC 1 & 200 & 03 & $05^{*}$ & 05 \\
\hline PMPC 2 & 200 & 00 & 00 & 00 \\
\hline PMPC 3 & 200 & 00 & 00 & 00 \\
\hline
\end{tabular}

$\mathrm{N}$ : $\mathrm{n}^{\circ}$ Units tested; P: Pressure; V: Volume

Table 4: Results amount of non-conforming samples found for the volumetric capacity and overflow test for the laboratory lots.

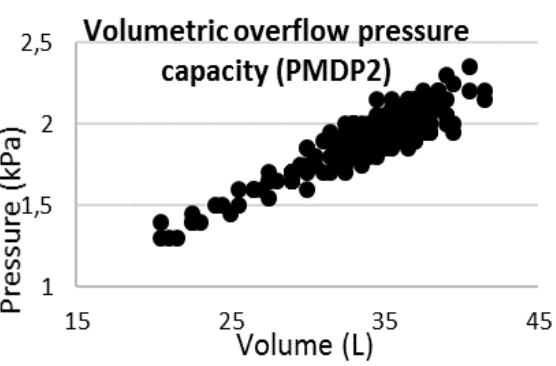

Figure 1: Graph of the volumetric capacity and overflow pressure of lots PMDP 1 and PMDP 2.

By the characteristics of the graphs, we can notice variability in the batches of manufacture, both in the pulverized batches as well as in the tests carried out with condoms of the same manufacturing lot. This can be explained by being a mass produced product, by the influence of latex film properties that depend on the original latex, the type of storage up to use, the maturation time of the latex, the dispersion, the composition (latex+Dispersion), immersion and vulcanization conditions and storage time after dipping and before product finalization. What stands out the importance of beyond certification, a monitoring analysis versus control analysis versus fiscal analysis, because it is a heterogeneous product in each manufacturing batch.

The Table 5 shows that the burst pressure averages ranged from 1,896 to $2,130(\mathrm{kPa})$ and those in the volume between 33.732 and 38.945 (L). Considering the standard error and that Lots PMPC1, PMPC2, PMPC3 are manufacturing lots sprayed, there is no statistical equivalence for both pressure and volume and can be considered as intrinsic limitations to the test method and the variability of the condoms that are manufactured in pasta.

\section{Determination of the integrity of the packaging}

Regarding the test for the determination of the integrity of the packaging, the laboratory batch PMPC 3 presented a non-conforming unit.

\section{Determination of holes}

Considered the most important test in quality control for male condoms, we identified 7 non-conforming units in one of the laboratory batches PMPC3. The Figure 3 shows one of the condom units where micro holes were found in the orifice determination test.

\section{Complementary tests}

The complementary tests of microbiological evaluation and of cytotoxicity, using the in vitro study using cell cultures, in the laboratory lots were carried out. The Table 6 shows the results found for the microbiological evaluation test in the laboratory lots.

The degree of cytotoxicity is quantified on a scale of 0 to 4 as shown in Table 7 . The sample is considered satisfactory if no culture exposed to the test sample shows cytotoxicity higher than grade 2 (mild cytotoxicity).

The Table 8 shows the results found for the laboratory batch cytotoxicity test. 
Citation: Duarte JT, de Almeida AECC, de Mello Pereira Abrantes S (2017) Products Sanitary Surveillance: Latex Condom on the Bias of the Sanitary Risk. J AIDS Clin Res 8: 700. doi: 10.4172/2155-6113.1000700
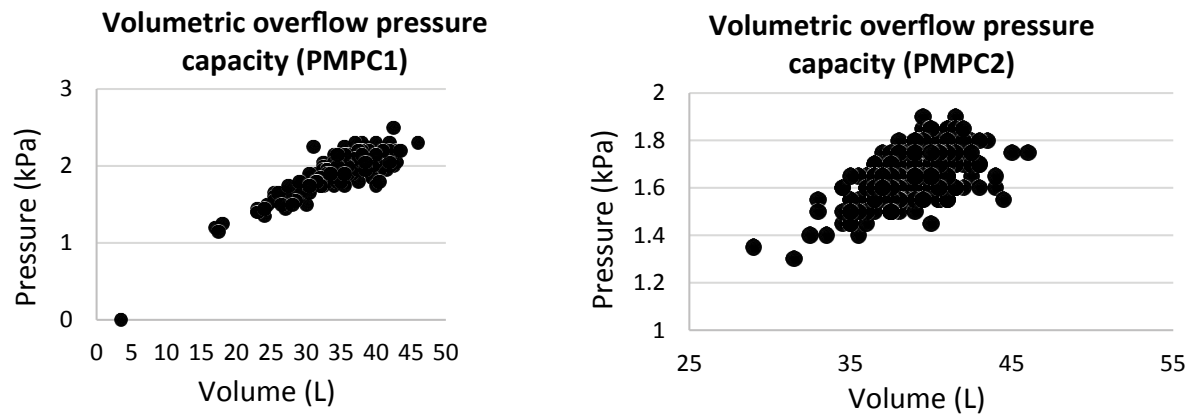

Volumetric overflow pressure capacity

(PMPC3)

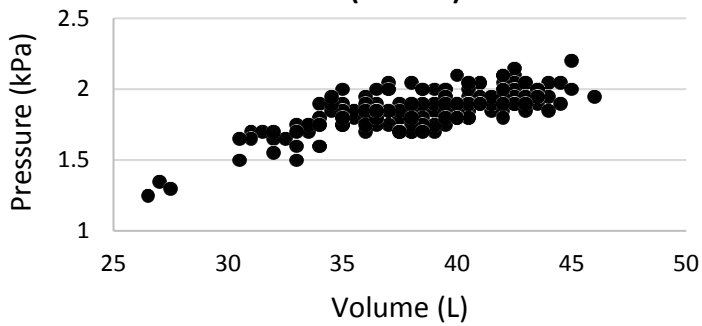

Figure 2: Graph of the volumetric capacity and overflow pressure of lots PMPC 1, PMPC 2 and PMPC 3, respectively.

\begin{tabular}{|c|c|c|c|c|c|c|c|c|}
\hline \multirow[b]{2}{*}{ LABORATORY LOTS } & \multicolumn{4}{|c|}{ Pressure $(\mathrm{kPa}) \mathrm{dm}^{3} \mathrm{~min}^{-1}$} & \multicolumn{4}{|c|}{ Volume $\left(\mathrm{dm}^{3}\right)$} \\
\hline & $\bar{x}$ & $\mathbf{s}$ & ep & Variance & $\bar{x}$ & $\mathbf{s}$ & ep & Variance \\
\hline PMDP1 & 2.130 & 0.175 & 0.012 & 0.031 & 37.662 & 3.622 & 0.256 & 13.120 \\
\hline PMDP2 & 1.896 & 0.189 & 0.013 & 0.036 & 33.732 & 4.120 & 0.291 & 16.977 \\
\hline PMPC1 & 1.930 & 0.255 & 0.018 & 0.065 & 34.535 & 5.147 & 0.363 & 26.494 \\
\hline PMPC2 & 1.655 & 0.114 & 0.008 & 0.013 & 38.945 & 2.617 & 0.185 & 6.849 \\
\hline PMPC3 & 1.866 & 0.139 & 0.009 & 0.019 & 38.777 & 3.761 & 0.266 & 14.142 \\
\hline
\end{tabular}

$\bar{x}:$ Average; s: standard deviation ep: Standard error

Table 5: Results of the dispersion measurements for the volumetric capacity and overflow pressure test of Laboratory Lots PMDP1, PMDP2, PMPC1, PMPC2 and PMPC3.

\begin{tabular}{|c|c|c|c|c|}
\hline & PMDP1 & PMDP2 & PMPC1 & + \\
\hline $\begin{array}{c}\text { Total aerobic bacteria } \\
\text { UFC/g }\end{array}$ & - & - & + & + \\
\hline Enterobacteria & - & - & - & - \\
\hline Staphylococcus aureus & - & - & + & - \\
\hline Pseudomonas aeruginosa & - & - & - & - \\
\hline Candida albicans & - & - & - \\
\hline Molds and yeasts & - & - & + \\
\hline Escherichia coli & - & - & - \\
\hline Pseudomonas stutzeri & - & - & + \\
\hline Citrobacter freundii & - & - & - \\
\hline Enterobacter cloacae & - & - & - \\
\hline
\end{tabular}

+: presence; -: absence

Table 6: Microorganisms found in laboratory batches. 
Citation: Duarte JT, de Almeida AECC, de Mello Pereira Abrantes S (2017) Products Sanitary Surveillance: Latex Condom on the Bias of the Sanitary Risk. J AIDS Clin Res 8: 700. doi: 10.4172/2155-6113.1000700
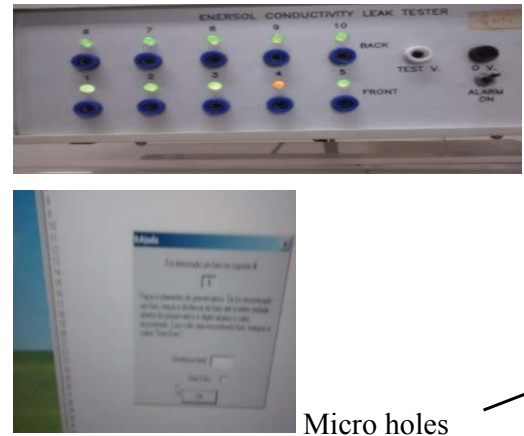

Micro holes

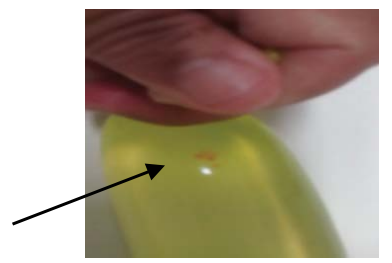

Figure 3: Micro holes found in the body of the male condom analyzed.

\begin{tabular}{|c|c|l|}
\hline Measure & Cytotoxicity & Description of the Cytotoxicity Zone \\
\hline $\mathbf{0}$ & Absence & No bleaching around or on the sample \\
\hline $\mathbf{1}$ & Light & Bleaching zone limited to the area under the sample \\
\hline $\mathbf{2}$ & Soft & $\begin{array}{l}\text { Bleaching zone size from the sample smaller than } 0.5 \\
\mathrm{~cm}\end{array}$ \\
\hline $\mathbf{3}$ & Moderate & Bleaching zone size from the sample of 0.5 to $1.0 \mathrm{~cm}$ \\
\hline $\mathbf{4}$ & Severe & $\begin{array}{l}\text { Bleaching zone size from the sample greater than } 1.0 \\
\mathrm{~cm}, \text { however, not involving the entire plate }\end{array}$ \\
\hline
\end{tabular}

Table 7: Degree of cytotoxicity.

\begin{tabular}{|c|c|c|}
\hline \multicolumn{2}{|c|}{ Degree of cytotoxicity } \\
\hline PMDP 1 & 2 & Soft \\
\hline PMDP 2 & 2 & Soft \\
\hline PMPC 1 & 2 & Soft \\
\hline PMPC 2 & 3 & Moderate \\
\hline PMPC 3 & 2 & Soft \\
\hline
\end{tabular}

Table 8: Results found for the laboratory batch cytotoxicity test.

The analyses are performed and identified all non-compliant manufacturing batches. Partial reports are drawn up and Sanitary Surveillance actions are requested to collect, according to the sampling established by RDC 62/2008, samples of manufacturing batches considered non-compliant at the initial stage of the sprayed sample. The Sanitary Surveillance seizes the requested lots, they return to the laboratory where the analyses are carried out. The reports are completed and sent to the Sanitary Surveillance for the necessary measures.

\section{Conclusion}

The developed model prints a new strand of systematized and active technovigilance for male condoms, joining a set of data, affirming itself by the use of physical, microbiological and cytotoxic analytical tests, made available by the Public Health laboratory, combining a technological information tool for mapping and traceability through the geoprocessing spatial analysis study, waving a path that allows directing Sanitary Surveillance actions, allowing the National Sanitary Surveillance System to respond adequately to the notifications received.

\section{References}

1. Scaramuzza MC (2014) DST'S.

2. Ministry of Health (2014) Secretariat of Health Surveillance. National STD and AIDS Program. Epidemiological Bulletin - AIDS/STD. Year III - $\mathrm{n}^{\circ} 1-01^{\mathrm{a}}-26^{\mathrm{a}}$ of January to June.

3. Bó MC (2007) Degradation of natural rubber male condoms: Data analysis process modeling and prediction of shelf life. Thesis (Ph.D. in Science, in Science and Technology of Polymers) - UFRJ, Rio de Janeiro, p: 316.

4. Rodrigues MJ (2010) Sexually transmitted diseases (STIs) in adolescence. Birth and Growth 19: 200.

5. International Organization for Standardization (1999) Sampling procedures for inspection by attributes - Part 1: Sampling schemes indexed by acceptance quality (AQL) for lot-by-lot inspection. Switzerland 87.

6. National Health Surveillance Agency (2002) Establishes the minimum requirements that should be complied with male condoms of natural rubber latex.

7. Population Information Program (2010) Center for Communication Programs.

8. Vera P, Pupo LR, Barboza R (2006) The right to prevention and the challenges of reducing vulnerability to HIV in Brazil. Rev Public Health 40: 109-119.

9. National Health Surveillance Agency (2002) Resolution RDC $n^{\circ}$ 62. It establishes the minimum requirements that must obey the male condoms of natural rubber latex.

10. Ministry of Health, Secretariat of Health Policies (2000) National STD and AIDS coordination. Legislation on STD and AIDS in Brazil.

11. Andrade T, Lurie P, Medina MG, Anderson K, Dourado I (2001) The opening of South America's first needle exchange program and an epidemics of crack use in Salvador, Bahia-Brazil. AIDS Behav 5: 51-64.

12. Ministry of Health, Secretariat for Health Policies (2000) National STD and AIDS Coordination. Legislation on STD and AIDS in Brazil.

13. Andrade T, Lurie P, Medina MG, Anderson K, Dourado I (2001) The opening of South America's first needle exchange program and an epidemics of crack use in Salvador, Bahia-Brazil. AIDS Behav 5: 51-64.

14. Enersol Consulting Engineers (2000) Elnflation 3, Sidney.

15. International organization for standardization (2002) Natural latex rubber condoms - requirements and test methods, Switzerland 46.

16. World Health Organization (2003) The male latex condom: Specification for condom procurement, Switzerland 100.

17. Gerofi J (2000) Latex condom manufacture. A condom. BMJ Books, London 230: 19-32.

18. International Organization for Standardization (2013) Biological evaluation and biocompatibility testing of medical devices, Switzerland. 